\title{
Changes in magnetic resonance imaging relaxation time on postmortem magnetic resonance imaging of formalin-fixed human normal heart tissue
}

\author{
Kiyokadzu Ebata ${ }^{1,2,6^{*}}$, Sakon Noriki ${ }^{3,6}$, Kunihiro Inai ${ }^{4,6}$ and Hirohiko Kimura ${ }^{5,6}$
}

\begin{abstract}
Background: Postmortem magnetic resonance imaging (MRI) has been used to investigate the cause of death, but due to time constraints, it is not widely applied to the heart. Therefore, MRI analysis of the heart after formalin fixation was previously performed. However, the changes in MRI signal values based on the fixation time of formalin were not investigated. The objective was to investigate changes over time in the T1- and T2-values of MRI signals in normal areas of hearts removed during autopsy, hearts subsequently fixed in formalin, and heart specimens sliced for the preparation of pathological specimens.
\end{abstract}

Methods: The study subjects were 21 autopsy cases in our hospital between May 26, 2019 and February 16, 2020 whose hearts were removed and scanned by MRI. The male:female ratio was 14:7, and their ages at death ranged from 9 to 92 years (mean age 65.0 19.7 years). Postmortem (PM)-MRI was conducted with a 0.3-Tesla (0.3-T) scanner containing a permanent magnet. A 4-channel QD head coil was used as the receiver coil. Scans were performed immediately after removal, post-formalin fixation, and after slicing; 7 cases were scanned at all three time points.

Results: The T1- and T2-values were calculated from the MRI signals of each sample organ at each scanning stage. Specimens were sliced from removed organs after formalin fixation, and the changes in T1-and T2-values over time were graphed to obtain an approximate curve. The median T1-values at each measurement time point tended to decrease from immediately after removal. The T2-values showed the same tendency to decrease, but this tendency was more pronounced for the T1-values.

Conclusion: MRI signal changes in images of heart specimens were investigated. Formalin fixation shortened both T1- and T2-values over time, and approximation formulae were derived to show these decreases over time. The shortening of T1- and T2-values can be understood as commensurate with the reduction in the water content (water molecules) of the formalin-fixed heart.

Keywords: Formalin fixation, Heart, Autopsy, Magnetic resonance imaging, Cause of death, Relaxation time

*Correspondence: ebatakiyokadzu@gmail.com

${ }^{1}$ Integrated and Advanced Medical Course, Graduate School of Medical Sciences, University of Fukui, 23-3 Matsuoka Shimoaizuki, Eiheiji-cho, Yoshida-gun, Fukui 910-1193, Japan

Full list of author information is available at the end of the article

\section{Background}

Postmortem imaging (PMI) using computed tomography $(\mathrm{CT})$ and/or magnetic resonance imaging (MRI) to investigate the cause of death and elucidate the pathophysiology of a deceased person's condition from internal images of the corpse came into use in the late 1990s 
$[1,2]$. It is also known in different countries as "forensic radiology" [3] or "virtual autopsy" [4, 5] and, in Japan, it has been widely used and reported as "autopsy imaging" ( $\mathrm{Ai}$ ) since the turn of the millennium [6]. We ourselves have installed CT and MRI scanners specifically for postmortem use in a building adjacent to our university hospital, where we have engaged mainly in the Ai of autopsy patients from both within and outside the hospital, and we have conducted postmortem radiology-pathology correlation studies [7-11].

The commonly used PMI modalities include CT (PM$\mathrm{CT}$ ), as well as MRI (PM-MRI), ultrasound (US), and regular X-rays. Of these, CT is comparatively widely used. However, MRI generally provides better contrast resolution than CT, and since PM-MRI is capable of detecting conditions such as ischemic myocardium, muscle contusion, pediatric deformity, cervical spinal cord injury, and pulmonary artery thromboembolism that cannot be evaluated by superficial observations, given that PM-MRI can produce high-resolution images without the artifacts caused by body movements and vascular pulsation that are problems in clinical imaging, it is likely to improve the accuracy with which the cause of death can be established compared with PM-CT [12-19]. In the United Kingdom, PM-MRI has been introduced as an alternative to autopsy for investigating causes of death [20].

Myocardial infarction, one important cause of death, is difficult to diagnose because autopsy does not show any morphological changes in the heart within $6 \mathrm{~h}$ of onset. Cases of the detection of acute myocardial infarction in situ by 3-Tesla (3-T)-MRI [16] have been reported, as has the value of PM-MRI as a guide to autopsy in cases of sudden cardiac death [12]. Experiments on pig hearts have also shown that edema is detectable on T2-weighted imaging (T2WI) $3 \mathrm{~h}$ after myocardial infarction from total coronary artery occlusion [21].

Temporal limitations pose difficulties for PM-MRI of the human heart in situ. Because it is difficult to take about four hours for PM-MRI scanning before the autopsy, PM-MRI should be performed on formalin-fixed hearts after removal during autopsy.

Many studies involving MRI scanning of formalin-fixed organs have been published, but most studies addressed the relaxation time of brain tissue. Another study investigated changes in T1- and T2-values due to temperature changes in rat organs following formalin fixation after postmortem removal [22-36]. There has also been a study of the Achilles tendon [37].

In some studies, the T1- and T2-values of the formalinfixed human heart were measured with MRI [38, 39]; the T1- and T2-values were measured, but the elapsed time after formalin fixation was not evaluated. The elapsed time after formalin fixation affects the MRI signal and is a very important matter.

The objective of the present study was to investigate changes over time in the T1- and T2-values of MRI signals in normal areas of hearts removed during autopsy, hearts subsequently fixed in formalin, and heart specimens sliced for the preparation of pathological specimens, as a basic study for the evaluation of heart disease by PM-MRI.

\section{Methods}

\section{Subjects}

The subjects were 23 consecutive pathological autopsy performed at our hospital from May 26, 2019 to November 16, 2020. Two cases were excluded because one case with a congenital heart malformation and one case of a 1-day-old newborn with an extremely small heart structure in which a signal measurement region of interest (ROI) of the same size as the other cases could not be set were excluded.

The male:female ratio was 14:7, and their ages at death ranged from 9 to 92 years (mean age $65.0 \pm 19.7$ years) (Table 1). Data on the causes of death and cardiovascular risk of the subjects were examined based on their medical records (Additional file 1: Table S1).

This study was approved by The research ethics committee of University of Fukui (No. 20100064), and written, informed consent was obtained from the family of each deceased patient prior to autopsy for publication of the research and any accompanying images. A copy of the written consent is available for review by the Editor of this journal. This research conformed to the provisions of the Declaration of Helsinki. The datasets generated and/or analyzed during the current study are not publicly available.

\section{MR imaging}

Postmortem MRI was conducted at the Ai center of the University of Fukui with a 0.3-T AIRIS Vento containing a permanent magnet (Hitachi Medical Corporation, Tokyo, Japan). A 4-channel QD head coil was used as the receiver coil (Fig. 1).

\section{Calculations}

T1-values were calculated by the inversion recovery (IR) method. Inversion time (TI) was varied at 15 different time points between 20 and $2000 \mathrm{~ms}(\mathrm{~ms})$, and the T1-values were calculated from the Bloch equation by the non-linear least squares method using equation [40] (1).

$$
\mathrm{M}_{\mathrm{z}}(\tau)=\mathrm{M}_{0} \times\{1-2 \exp (-\tau / \mathrm{T} 1)\}
$$

The T2-values were calculated by the spin-echo method. The echo time (TE) was varied at 12 different 
Table 1 List of autopsy and PM-MRI cases

\begin{tabular}{|c|c|c|c|c|c|}
\hline Case no & Sex & Age (years) & Raw scan & Pre-cut scan (day) & Post-cut scan (day) \\
\hline Case 01 & M & 59 & & & $O(216)$ \\
\hline Case 02 & M & 72 & O & $O(10)$ & $O(72)$ \\
\hline Case 03 & M & 71 & O & & $O(177)$ \\
\hline Case 04 & M & 92 & & & $O(137)$ \\
\hline Case 05 & M & 62 & & & $O(43)$ \\
\hline Case 06 & $\mathrm{~F}$ & 79 & & $\mathrm{O}(15)$ & $\mathrm{O}(81)$ \\
\hline Case 07 & M & 78 & & $O(23)$ & $\mathrm{O}(78)$ \\
\hline Case 08 & M & 70 & O & $O(15)$ & $O(67)$ \\
\hline Case 09 & $\mathrm{~F}$ & 76 & O & $\bigcirc(18)$ & $O(41)$ \\
\hline Case 10 & M & 59 & O & $O(16)$ & $O(53)$ \\
\hline Case 11 & $\mathrm{~F}$ & 59 & O & $O(14)$ & $O(32)$ \\
\hline Case 12 & M & 76 & O & $O(18)$ & \\
\hline Case 13 & M & 20 & & $\mathrm{O}(14)$ & \\
\hline Case 14 & $\mathrm{~F}$ & 48 & & $O(25)$ & \\
\hline Case 15 & $\mathrm{~F}$ & 9 & & $\mathrm{O}(46)$ & \\
\hline Case 16 & M & 91 & & $O(12,19.27,33,40)$ & $O(59,82,108,121)$ \\
\hline Case 17 & $\mathrm{~F}$ & 75 & & & $\mathrm{O}(6,15,25,34,49,71)$ \\
\hline Case 18 & M & 75 & & $O(3,5,7,10,12,14,26)$ & O(39) \\
\hline Case 19 & $\mathrm{~F}$ & 52 & O & $O(5,7,14)$ & $O(37)$ \\
\hline Case 20 & M & 72 & O & $O(3,5,8,10,17)$ & $O(19,39)$ \\
\hline Case 21 & M & 71 & O & $O(7,10)$ & \\
\hline
\end{tabular}

Raw scan: MRI scanned after the heart had been washed out with physiological saline immediately after removal

Pre-cut scan: MRI scanned with the formalin-fixed heart thoroughly immersed in formalin solution

Post-cut scan: MRI scanned after the fixed heart had been sliced, with the specimen closest to the papillary muscles chosen for scanning by the same method as the raw and pre-cut scans

$M: F=14: 7$ Age $(y)$, mean $(S D)=65.0 \pm 19.7$

Pre-cut scan (day): scan day from death, mean $(S D)=15.4 \pm 10.0$

Post-cut scan (day): scan day from death, mean $(S D)=68.0 \pm 49.6$

time points between 10 and $200 \mathrm{~ms}$, and the values were calculated using Eq. (2).

$$
\mathrm{M}_{\mathrm{x}}(\tau)=\mathrm{M}_{0} \times \exp (-\tau / \mathrm{T} 2)
$$

ז: TE, $M_{z}(\tau)$ : longitudinal magnetization over $\tau, M_{0}$ : longitudinal magnetization at thermal equilibrium, $M_{x}(\tau)$ : transverse magnetization over $\tau$.

The T1-value takes $6 \mathrm{~min}$ and $15 \mathrm{~s}$ per measurement, with an additional $15 \mathrm{~s}$ of pre-scanning required between each measurement. This measurement was performed 15 times. The T2-value takes $6 \mathrm{~min}$ and $28 \mathrm{~s}$ per measurement; for the T2-value, this measurement was performed 12 times. Before starting a series of MRI scans, images need to be taken to determine the position to scan and the cross-section of each specimen. This imaging series to determine the scan position took about 10-15 min each for one specimen, and since the measurement of T1- and T2-values was planned and measured as a series of consecutive scans, the start-to-finish imaging time per specimen was typically $3.5-4 \mathrm{~h}$.

\section{Scan conditions}

In order to make sure that the heart was sufficiently still in the container, a resting time was provided. In addition, time was set aside for the heart to remain in place for at least $30 \mathrm{~min}$ after being set in the scan position to ensure that the heart in the special container was shaken as little as possible in the solution by the movement of setting the container with the heart in the MRI gantry. After the resting time was secured, a series of measurements was started by changing TI and TE (Tables 2,3 ). This sequence of procedures from setting the specimen to imaging was performed for all measurements investigated in this study.

As mentioned at the beginning, the purpose was to measure the relaxation time of non-pathological parts of the heart structure. Therefore, it was necessary to confirm that the ROI was normal myocardial tissue.

In 11 cases, the blood was washed out of the heart with physiological saline immediately after its removal during the autopsy, after which the removed heart was immersed 

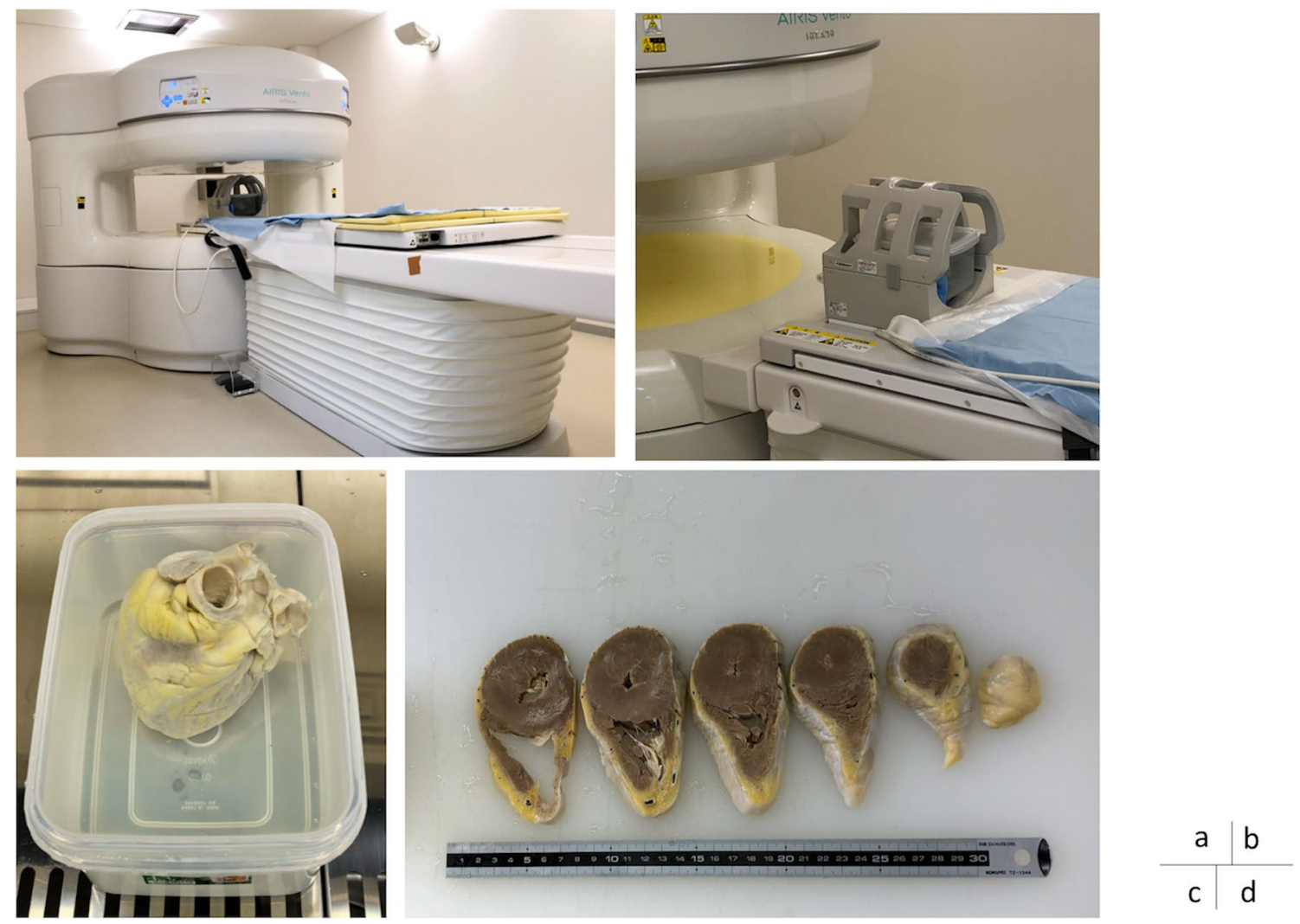

Fig. 1 a External view of the MRI scanner. b QD coil. c Formalin-fixed heart. d Sliced heart

Table 2 PM-MRI Parameters. MRI pulse sequence scanning conditions

\begin{tabular}{lll}
\hline & T1-value & T2-value \\
\hline TR & 3000 & 3000 \\
TE & 10.0 & Table3 \#2 \\
TI & Table3 \#1 & - \\
FA & 90 & 90 \\
Thickness & 5.0 & 5.0 \\
FOV & 200 & 200 \\
Scan time & $6^{\prime} 15^{\prime \prime} \times 15$ & $6^{\prime} 28^{\prime \prime} \times 12$ \\
\hline
\end{tabular}

TR: time of repeat (millisecond)

TE: echo time (millisecond)

TI: inversion time (millisecond)

FA: flip angle (degree)

FOV: field of view (millimeter) in physiological saline and scanned by MRI. This MRI scan immediately after removal was termed the "raw scan."

In 16 cases, the heart was scanned by MRI under the same scanning conditions as the raw scan after it had been fixed by immersion in formalin, and this was termed the "pre-cut scan". If time permitted, consecutive scans were performed under the same conditions. A total of 33 pre-cut scans of these 16 specimens were conducted.

In 16 cases, the formalin-fixed, removed heart was sliced into sections parallel to the annulus for the preparation of pathological tissue specimens, and the approximately 2-cm-thick slices were thoroughly soaked in formalin. They were then left for at least $6 \mathrm{~h}$ in the MRI gantry before being scanned under the same conditions as those used for the raw and pre-cut scans. These were termed the "post-cut scans." If time permitted, consecutive scans were

Table 3 PM-MRI parameters. TI and TE assigned for signal acquisition to obtain T1 and T2-values

\begin{tabular}{|c|c|c|c|c|c|c|c|c|c|c|c|c|c|c|c|}
\hline \#1:T1-value & 20 & 30 & 40 & 50 & 60 & 80 & 100 & 150 & 200 & 300 & 400 & 500 & 700 & 1000 & 2000 \\
\hline \#2:T2-value & 10 & 20 & 30 & & 40 & 50 & 60 & 80 & 100 & 120 & & 140 & 150 & 160 & 200 \\
\hline
\end{tabular}


performed under the same conditions. A total of 25 postcut scans of these 16 specimens were conducted.

In 7 patients, MRI was successfully performed at all three stages (immediately after removal, post-fixation, and after slicing).

\section{Region of interest designation}

The specimens were sampled, and regions of interest (ROIs) for signal measurement were designated in consecutive slices that had been microscopically confirmed by the pathologist to be structural tissue with no apparent pathological changes (Figs. 2, 3).

The ROIs used for all measurements were circular, $10 \mathrm{~mm}$ in diameter, in all cases. In addition, before measurement, the location of the ROI was always checked in detail for each specimen to ensure that it was the same location.

\section{Temperature management and temperature measurements}

To investigate the effect of temperature changes before and after MRI scanning of the specimens, the temperatures of the MRI chamber and of the specimens before and after MRI scanning were measured. The MRI chamber was air-conditioned to a constant $23{ }^{\circ} \mathrm{C}$ for $24 \mathrm{~h}$ a day. Solution temperatures were measured using a Quick Check SN-820 core thermometer (Netsuken, Tokyo, Japan). The surface temperature of the specimens was measured using an infrared thermometer Model SK-8940 (Sato Keiryoki Mfg. Co., Ltd., Tokyo, Japan). A solution generator was used for the formalin solution, and a stable solution concentration was obtained.

\section{Statistical analysis}

The accumulated data were stored in a database, operating behind a firewall, and password-protected. Data extracts were exported to Microsoft Excel (Microsoft Corp., Redmond, WA, USA). To check the normality of the distribution of the measured values of $\mathrm{T} 1$ and $\mathrm{T} 2$, the Kolmogorov-Smirnov test was performed and showed normal distributions. Then, the coefficient of determination $\left(\mathrm{R}^{2}\right)$ was calculated. The sample size was calculated to be 20 cases at a significance level of $5 \%$, power of $80 \%$, and correlation coefficient of 0.6. All statistical analyses were performed with EZR (Saitama Medical Center, Jichi Medical University, Saitama, Japan), which is a graphical user interface for R (The R Foundation for Statistical Computing, Vienna, Austria) [41]. The relationships of
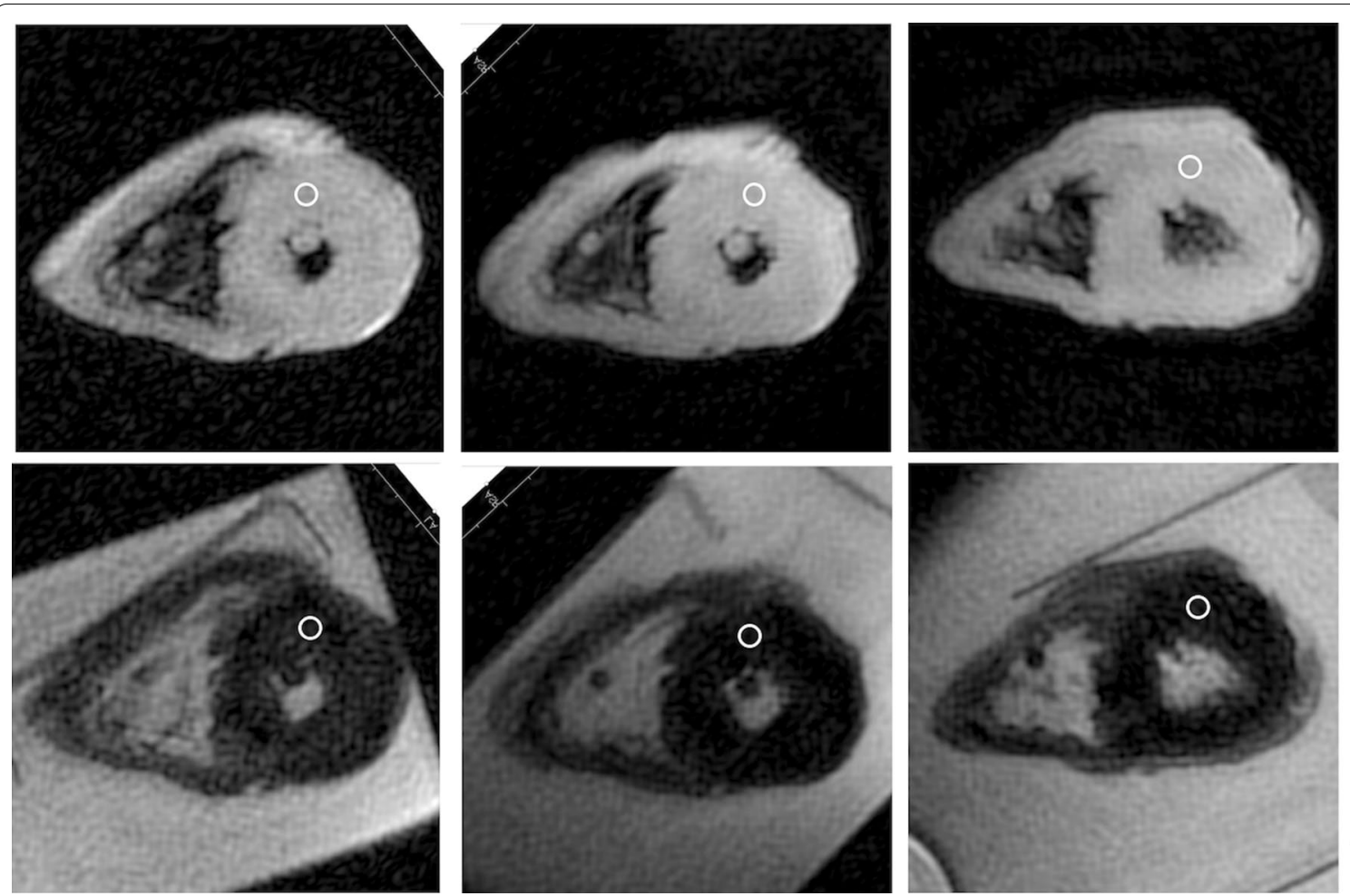

\begin{tabular}{l|l|l}
$a$ & $b$ & $c$ \\
$d$ & $e$ & $f$
\end{tabular}

Fig. 2 Case 9 a T1-value image Raw scan TI=1000 ms. b T1-value image Pre-cut scan (18 days) Tl=1000 ms. c T1-value image Post-cut scan (41 days) TE $=200 \mathrm{~ms} \mathbf{d}$ T2-value image Raw scan TE $=200 \mathrm{~ms}$. e T2-value image Pre-cut scan (18 days) TE = $200 \mathrm{~ms}$. f T2-value image Post-cut scan (41 days) $\mathrm{TE}=200 \mathrm{~ms}$ 

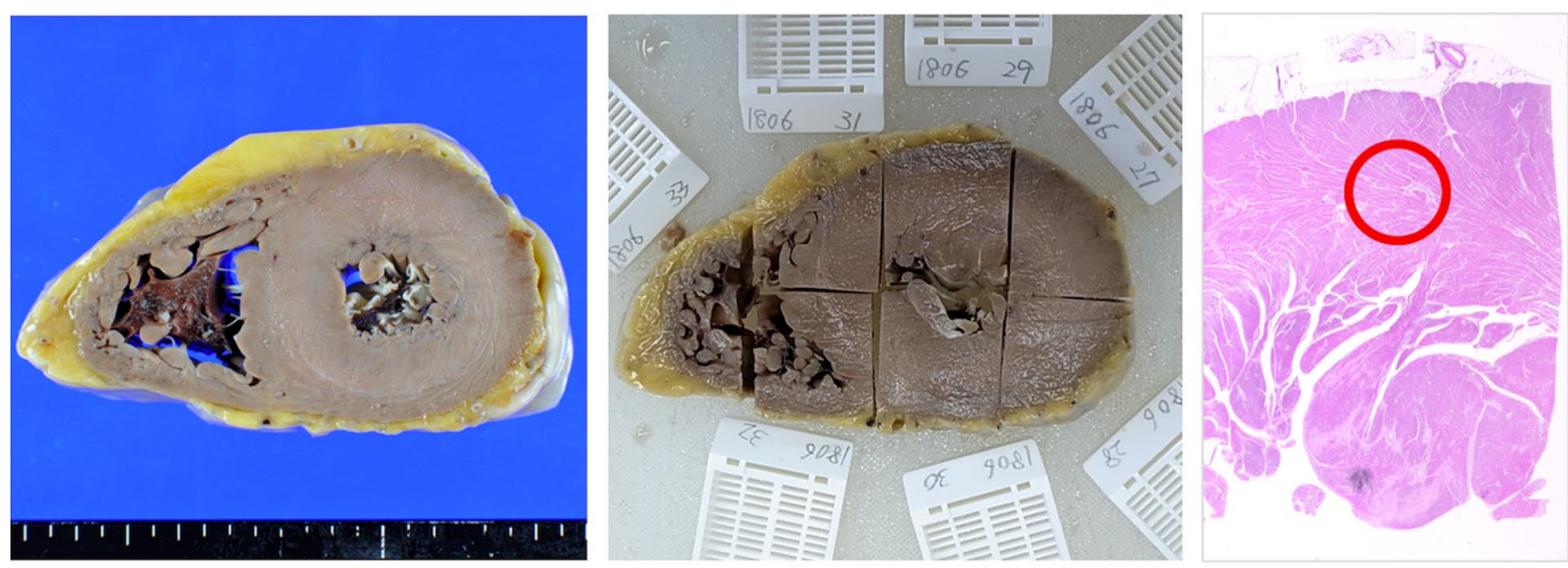

$\mathrm{a}|\mathrm{b}| \mathrm{c}$

Fig. 3 Case 9 a Sliced specimen. b Sampling. c Magnified view. The red circle indicates the ROI

the T1- and T2-values to the time course were fitted to the curve-fitting routine of Excel.

\section{Results}

The T1- and T2-values were calculated from the MRI signals of each sample organ at each of the scanning stages (raw scan, pre-cut scan, and post-cut scan). The values obtained over time from organ removal were displayed graphically.

Raw scans: T1- and T2-values were measured in 11 samples of regions pathologically diagnosed as normal in hearts scanned by MRI immediately after removal. The shortest T1-value was $349.7 \mathrm{~ms}$, and the longest was $453.3 \mathrm{~ms}$; the median value was $411.7 \mathrm{~ms}$, and the mean value was $407.5 \pm 21.6 \mathrm{~ms}$. The shortest T2-value was $62.4 \mathrm{~ms}$, and the longest was $87.6 \mathrm{~ms}$; the median value was $77.1 \mathrm{~ms}$, and the mean was $77.6 \pm 6.0 \mathrm{~ms}$.

Pre-cut scans: The mean time from the start of fixation to scanning of the specimens scanned at this stage was $15.4 \pm 10.0$ days. The shortest time was 3 days, and the longest was 46 days. T1 - and T2-values were measured in 16 specimens. The shortest T1-value was $193.8 \mathrm{~ms}$, and the longest was $258.1 \mathrm{~ms}$; the median was $226.7 \mathrm{~ms}$, and the mean was $223.2 \pm 16.0 \mathrm{~ms}$. The shortest T2-value was $50.5 \mathrm{~ms}$, and the longest was $62.5 \mathrm{~ms}$; the median was $54.4 \mathrm{~ms}$, and the mean was $55.2 \pm 3.2 \mathrm{~ms}$.

Post-cut scans: The mean time from the start of formalin fixation to scanning of the specimens scanned at this stage was $68.0 \pm 49.6$ days. The shortest time was 6 days, and the longest was 216 days. The shortest T1-value was $133.8 \mathrm{~ms}$, and the longest was $221.8 \mathrm{~ms}$; the median was $172.5 \mathrm{~ms}$, and the mean was $175.4 \pm 21.3 \mathrm{~ms}$. The shortest T2-value was $47.3 \mathrm{~ms}$, and the longest was $65.0 \mathrm{~ms}$; the median was $51.6 \mathrm{~ms}$, and the mean was $53.4 \pm 4.7 \mathrm{~ms}$ (Table 4).

The changes over time in T1- and T2-values from organ removal to scanning as sliced specimens were graphed, and the power approximation curves were calculated (Figs. 4, 5). The median T1-values at each measurement time point tended to decrease from immediately after removal, with the median $\mathrm{T} 1$-value from cut tissue after formalin fixation shortened to approximately 55\% of that immediately after removal. The median T1-value decreased to approximately $42 \%$ during the interval from the raw scan immediately after removal to the post-cut scan.

T2-values at each measurement time point tended to decrease from immediately after removal, with the median T2-value from cut tissue after formalin fixation shortened to approximately $70 \%$ of that immediately after removal. The median $\mathrm{T} 2$-value decreased to approximately $67 \%$ during the interval from immediately after removal to MRI scanning of the sliced specimen. The T2-value exhibited the same tendency to decrease as the T1-value, but this tendency was more pronounced for the T1-value.

For the T1-values, the equation derived from all data from the raw scan to the post-cut scan was $y=379.22 \mathrm{x}^{-}$ 0.187 , with $\mathrm{R}^{2}=0.9083$. For the $\mathrm{T} 2$-values, the equation derived from all data was $\mathrm{y}=72.239 \mathrm{x}^{-0.088}$, with $\mathrm{R}^{2}=$ 0.6597 . There was no specimen in which either the $\mathrm{T} 1$ or $\mathrm{T} 2$ signal value lengthened over time.

In cases 16 to 21 , multiple scans of the same sample were taken. The approximation curves for these multiple scans of the same sample were $y=352.92 x-0.16, R^{2}=$ 0.8522 for $\mathrm{T} 1$ and $\mathrm{y}=72.045 \mathrm{x}-0.091, \mathrm{R}^{2}=0.5954$ for 
Table 4 T1- and T2-values of each case

\begin{tabular}{|c|c|c|c|c|c|}
\hline Scan-timing & Case & T1-value & Median / mean \pm SD & T2-value & Median $/$ mean \pm SD \\
\hline \multirow[t]{11}{*}{ Raw scan } & 2 & 427.9 & \multirow[t]{11}{*}{$411.7 / 407.5 \pm 21.6$} & 77.1 & \multirow[t]{11}{*}{$77.1 / 77.6 \pm 6.0$} \\
\hline & 3 & 411.7 & & 78.7 & \\
\hline & 8 & 453.3 & & 87.6 & \\
\hline & 9 & 374.3 & & 69.0 & \\
\hline & 10 & 383.5 & & 76.0 & \\
\hline & 11 & 418.5 & & 62.4 & \\
\hline & 12 & 409.7 & & 73.9 & \\
\hline & 17 & 349.7 & & 74.5 & \\
\hline & 19 & 403.4 & & 84.6 & \\
\hline & 20 & 421.7 & & 82.7 & \\
\hline & 21 & 428.4 & & 87.2 & \\
\hline \multirow[t]{16}{*}{ Pre-cut scan } & 2 & 213.3 & \multirow[t]{16}{*}{$226.7 / 223.2 \pm 16.0$} & 59.7 & \multirow[t]{16}{*}{$54.4 / 55.2 \pm 3.2$} \\
\hline & 6 & 258.1 & & 54.1 & \\
\hline & 7 & 224.0 & & 59.6 & \\
\hline & 8 & 225.6 & & 53.6 & \\
\hline & 9 & 195.2 & & 52.6 & \\
\hline & 10 & 231.2 & & 52.3 & \\
\hline & 11 & 204.4 & & 62.5 & \\
\hline & 12 & 227.8 & & 61.5 & \\
\hline & 13 & 234.0 & & 51.0 & \\
\hline & 14 & 193.8 & & 51.4 & \\
\hline & 15 & 196.1 & & 52.4 & \\
\hline & $16^{*}$ & 208.2 & & 54.6 & \\
\hline & $18^{*}$ & 235.6 & & 58.2 & \\
\hline & $19^{*}$ & 231.7 & & 54.6 & \\
\hline & $20^{*}$ & 254.7 & & 55.1 & \\
\hline & $21^{*}$ & 238.0 & & 50.5 & \\
\hline \multirow[t]{16}{*}{ Post-cut scan } & 1 & 135.5 & \multirow[t]{16}{*}{$172.5 / 175.4 \pm 21.3$} & 47.3 & \multirow[t]{16}{*}{$51.6 / 53.4 \pm 4.7$} \\
\hline & 2 & 144.9 & & 47.8 & \\
\hline & 3 & 133.8 & & 50.1 & \\
\hline & 4 & 159.0 & & 60.0 & \\
\hline & 5 & 160.5 & & 49.3 & \\
\hline & 6 & 165.2 & & 53.0 & \\
\hline & 7 & 167.9 & & 57.6 & \\
\hline & 8 & 194.7 & & 65.0 & \\
\hline & 10 & 166.5 & & 48.9 & \\
\hline & 11 & 178.3 & & 49.5 & \\
\hline & 12 & 178.8 & & 61.5 & \\
\hline & $16^{*}$ & 177.0 & & 48.3 & \\
\hline & $17^{*}$ & 221.8 & & 57.3 & \\
\hline & 18 & 210.0 & & 55.0 & \\
\hline & 19 & 220.0 & & 49.0 & \\
\hline & $20^{*}$ & 192.7 & & 55.1 & \\
\hline
\end{tabular}

* Consecutive scans were performed under the same conditions. The signal averages of 22 Pre-cut scans of these 5 specimens were taken. The signal averages of 12 Post-cut scans of these 3 specimens were taken (See Table 1) 


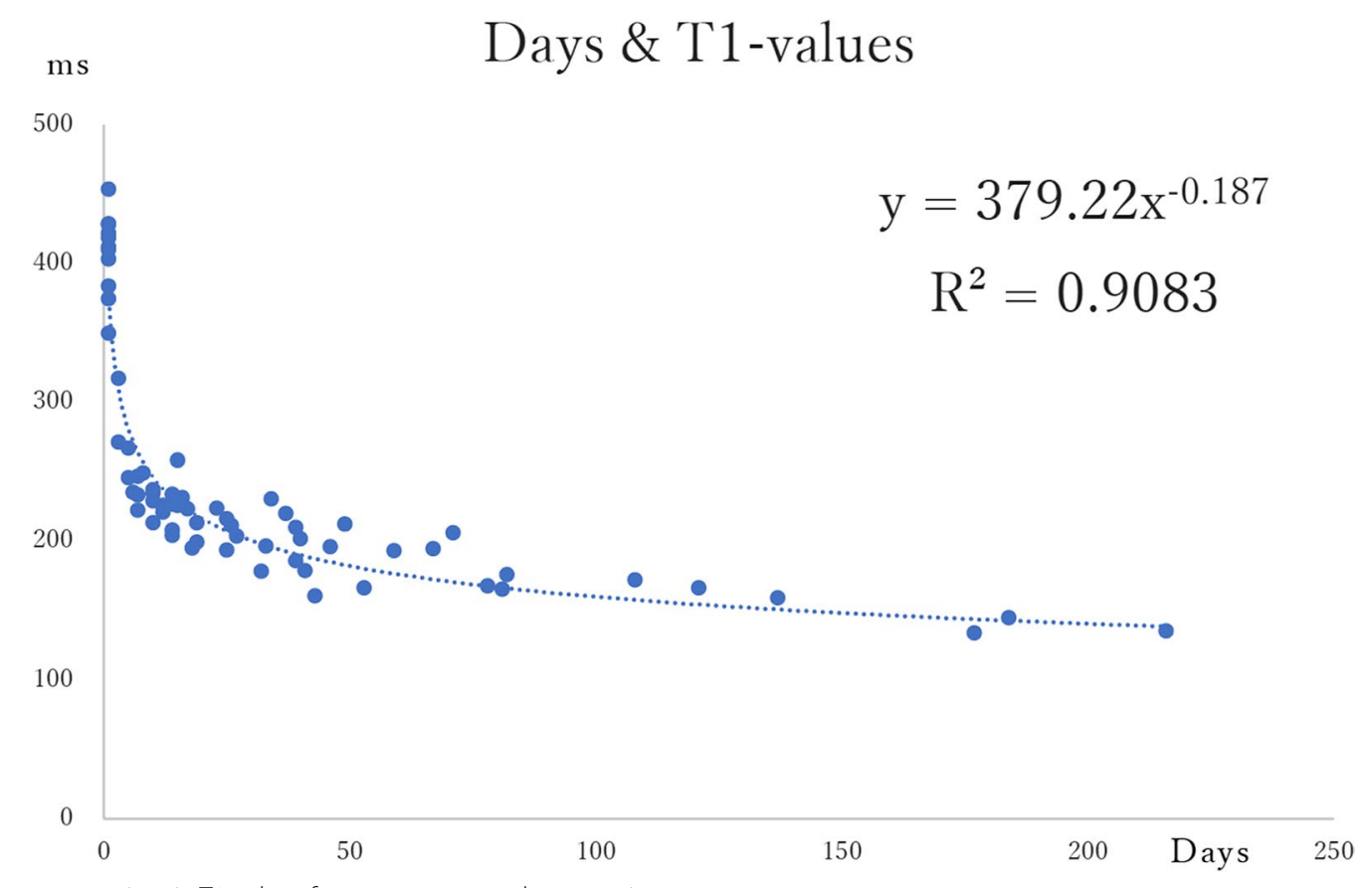

Fig. 4 Changes over time in T1-values from organ removal to scanning

\section{Days \& T2-values}

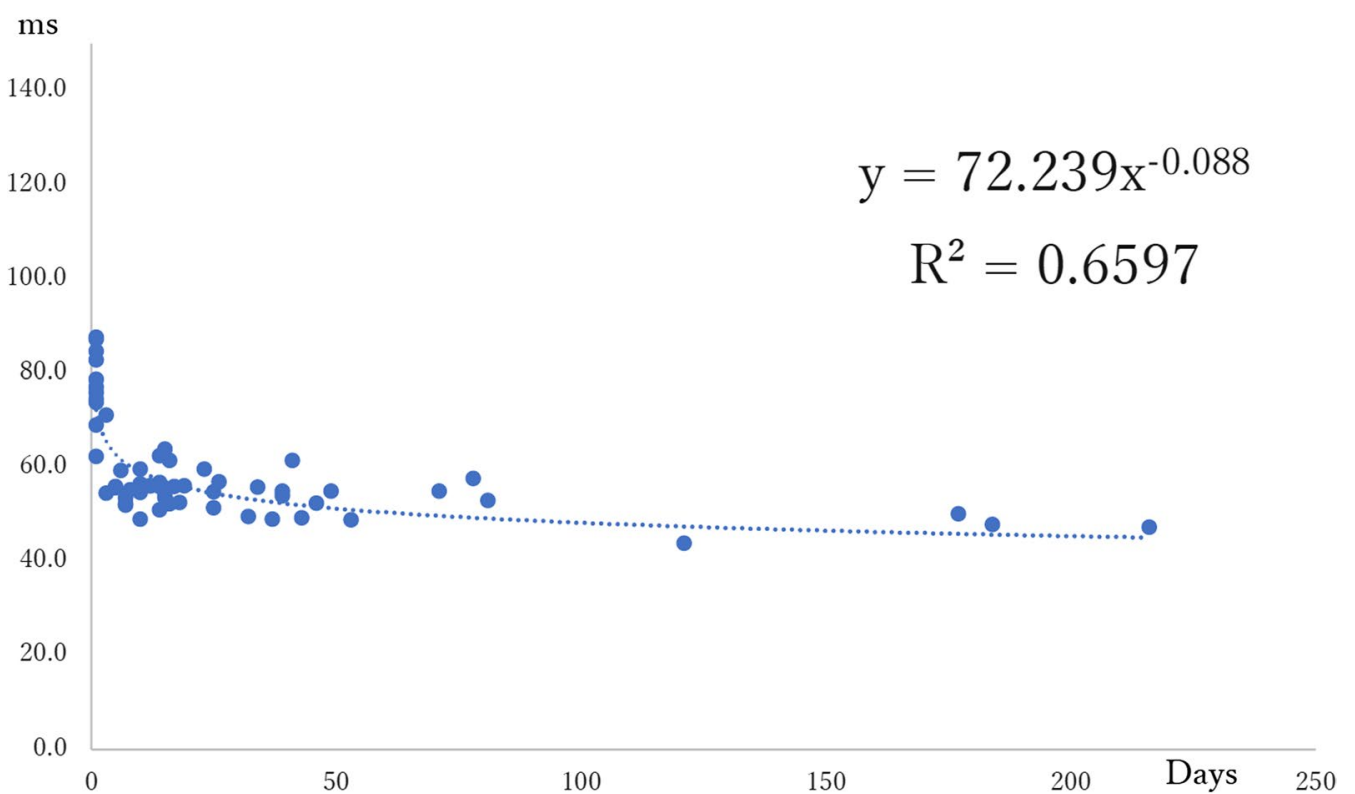

Fig. 5 Changes over time in T2-values from organ removal to scanning 
T2. Although the reliability of both T1- and T2-values was lower than that of the complete data, they did not show significant differences. (Additional file 2: Figures S1, Additional file 3: Fig. S2)

Temperature measurements of each heart before and after each series of scans showed that the temperature of the laboratory did not change by more than $1{ }^{\circ} \mathrm{C}$ over this time, and changes in specimen surface temperature were also within the range $\pm 0.5^{\circ} \mathrm{C}$.

\section{Discussion}

In this study, signal changes in images of specimens were investigated on the basis of data numerically converted from T1- and T2-values. It was found that formalin fixation shortened both T1- and T2-values over time, and approximation formulae were derived to show these decreases over time.

In the present study, it was necessary to cut the specimen at some point and examine the pathological image in order to determine whether it was a normal site. Therefore, it was necessary to cut the heart in order to target the normal part for signal measurement. The signal changes of the specimens after cutting were also measured. In order to observe longer term signal changes, the signal changes of the specimens after cutting were also measured based on the findings from the histopathological specimens.

The heart specimens showed a gradual curve of signal change over time, with no steep signal change due to the continued fixation in formalin solution after cutting.

As yet, no scientific findings that might explain the effect of formalin fixation in shortening T1- and T2-values have been identified. However, formalin fixation inhibits the progression of autolysis and decay that starts the moment tissues are harvested, and the principle of fixation lies in the structure of formaldehyde. When aldehyde groups react with the amine groups on protein sidechains, hydroxymethyl groups, which further react with amine groups to form methylene bridges that stabilize the proteins (bridge fixation), are generated. This bridge formation actually "fixes" proteins so that they are unable to denature. This is believed to make them more stable [42].

The rate at which formalin solution penetrates the tissue has been reported to be $2.4 \mathrm{~mm}$ in $24 \mathrm{~h}$ for formaldehyde by observation and prediction [43]. The mean thickness of the left ventricular myocardial wall at the ROI site in the present study was $12.66 \mathrm{~mm}$ in all patients, and the mean thickness of the myocardial wall at the ROI site was $13.3 \mathrm{~mm}$ in men and $11.5 \mathrm{~mm}$ in women. Formalin reaches the heart deeply from both the luminal and epicardial sides. In the present study, the shortest period after formalin fixation when MRI was performed was in case 18 and case 20; myocardial wall thickness at the ROI site was $12.0 \mathrm{~mm}$ and $13.0 \mathrm{~mm}$, respectively. In both cases, the thickness of the myocardial wall was within $14.4 \mathrm{~mm}(2.4 \mathrm{~mm} \times 2 \times 3$ days $)$.

The shortening of T1- and T2-values can be understood as commensurate with a reduction in the water content (water molecules) of the organ concerned. The following are two possible reasons for this reduction in water content.

The first is that tissue generally contracts as a result of fixation with formaldehyde, as described above. Formalin fixation reduces the distance between proteins, so that, although there are differences due to the structural content of particular tissues, in general the tissue contracts, physically expelling the water contained within it, reducing the water content per unit volume of the specimen.

Another possibility is tissue dehydration. The undiluted formaldehyde solution is dissolved in anhydrous to a $35-37 \%$ solution. This means that $10 \%$ formalin solution contains $10 \%$ formaldehyde solution, so a simple formalin fixation solution contains $10 \%$ methanol. Because methanol has a powerful dehydrating effect, this may therefore exert a dehydrating action by draining water from the tissue. It is thus a reasonable conjecture that these two effects may act synergistically to shorten the T1- and T2-values.

It was possible to express this shortening of the T1- and T2-values due to formalin fixation in the form of approximation equations, suggesting that, if the time elapsed since the start of formalin fixation is known, it may be possible to estimate the T1- and T2-values of heart tissue without apparent pathological change at the start of formalin fixation. Once the T1- and T2-values for different conditions (diseases), rather than normal tissue, have been measured, MRI signal values may become useful for analyzing pathological conditions at all time points.

In previous studies, the tissue relaxation time depended on the magnetic field, temperature, time after resection, and in vivo or in vitro conditions [44-47]. Since the rates of change of $\mathrm{T} 1$ and $\mathrm{T} 2$ relaxation times vary depending on the tissue, it has already been pointed out that the contrast of the image varies depending on the organ under study, the condition of the tissue, and the strength of the magnetic field.

The graphs of the T2-values exhibited greater variation than did those for the T1-values. This may have been because the MRI scanner used for measurements had a magnetostatic field strength of 0.3-T, and in light of the fact that the range of the signal measurements that exhibited this variation was within a 10 -ms range, a major reason may have been that signal acquisition was being performed in a measurement range close to the limit of accuracy of the MRI scanner for measuring signal values. 
It is possible that, because the inversion recovery (IR) method was used to measure T1-values from gradually increasing signals, it was possible to obtain higher values, but because the spin echo (SE) method was used to measure T2-values, the fact that faint MRI signals that were gradually decreasing were measured may have caused greater variation of T2-values than of T1-values. One method of ascertaining whether this is the case would be to extend the recovery time (TR) in the SE method and increase the number of measurement points with a long TE, thus decreasing measurement error, but in the present study, MRI signals were measured consecutively over a period of more than $6 \mathrm{~h}$, making it unrealistic to further prolong the TR or increase the number of measurement points. When the variation in $\mathrm{T} 2$ signal values is plotted on the vertical scale on the graph, the extent of variation is not very great compared with the T1-values.

Let us consider the graph on which the T2-values are plotted. It is known that the SE method, which is optimized to some extent, has less error in measurement. However, the static magnetic field strength of the MRI system used in this study was $0.3 \mathrm{~T}$. The values obtained at this static field strength of course contain errors due to the multiplication of the noise factor inherent to the machine and the noise factor contained in the sample. The measurement range of the obtained T1-values was about $150 \mathrm{~ms}$ to $200 \mathrm{~ms}$ in the time phase after the cut. In comparison, the measurement range of the T2-value was very short, about 50 to $60 \mathrm{~ms}$ in the time phase after the cut. When the vertical axis scales of the graphs obtained for T1- and T2-values were aligned, the T2-value curve was measured in such a time range that it appeared to be almost linear.

Since this was a 0.3-T MRI system, we believe that it had reached the range where the measurement limit must be considered. The TR for the SE method was set at $3000 \mathrm{~ms}$ this time. If the TR is extended further, the resulting signal will be even weaker. The TR time for MRI signal acquisition is determined by considering the reliability of the obtained values. The limit of signal acquisition with a properly chosen SE method also needed to be considered depending on the device.

Temperature changes also reportedly affect MRI signals, [48] but temperature measurements of each heart before and after each series of scans showed that the temperature of the laboratory did not change by more than $1{ }^{\circ} \mathrm{C}$ over this time, and changes in specimen surface temperature were also within the range of around $0.5^{\circ} \mathrm{C}$. This indicated that the effect of temperature changes could be excluded.

There were four limitations to this study. The first was that only areas assessed to be normal heart tissue structures on histopathological specimens were investigated.
We intend to carry out further studies of diseased areas in the future. The second was that a 0.3-T device was used for the study. However, we consider that data from 0.3-T devices will be important for the practice of PMMRI on removed hearts in the future. The third was that, although the specimens investigated in this study came from a total of 21 patients, it was possible to carry out MRI scanning at all stages of specimen preparation in only 7 , and further studies of larger numbers of cases will be required in the future.

Finally, the temperature changes in the myocardial wall tissue during "raw scan" imaging were not clearly investigated. Temperature measurements were monitored at the beginning and at the end of the scan. Considering the time lapse from the post-extraction state to the start of the scan, it was thought that extreme temperature changes could be avoided.

\section{Conclusion}

MRI signal changes in images of heart specimens were investigated. Formalin fixation shortened both T1- and T2-values over time, and approximation formulae were derived to show these decreases over time.

\section{Abbreviations}

PM: Postmortem; MRI: Magnetic resonance imaging; PMI: Postmortem imaging; CT: Computed tomography; Ai: Autopsy imaging; US: Ultrasound; T2WI: T2-weighted imaging; IR: Inversion recovery; TI: Inversion time; ms: Milliseconds; TE: Echo time; ROls: Regions of interest; T1Wl:T1-weighted imaging; T2*: T2 star; FLAIR: Fluid-attenuated inversion-recovery; SE: Spin echo; TR: Recovery time.

\section{Supplementary Information}

The online version contains supplementary material available at https://doi. org/10.1186/s12880-021-00666-5.

Additional file 1. The cause of death and data on subjects' cardiovascular risk.

Additional file 2. The changes of T1-value in relaxation time of the same specimens from Case 16 to 21 . The approximate curve of the values obtained by multiple scans with the same sample is shown.

Additional file 3. The changes of T2-value in relaxation time of the same specimens from Case16 to 21. The approximate curve of the values obtained by multiple scans with the same sample is shown.

\section{Acknowledgements \\ Not applicable.}

\section{Authors' contributions}

Sakon Noriki: Conceptualization, Methodology, Visualization, Validation. Kunihiro Inai: Methodology, Resources. Hirohiko Kimura: Project administration, Supervision, Formal analysis. All authors read and approved the final manuscript

\section{Funding}

This report was partially supported by the Nakatani Foundation for advancement of measuring technologies in biomedical engineering to S. Noriki (Development Research Grant), and a Grant-in-Aid for Scientific Research 
(B) from the Ministry of Education, Culture, Sports, Science and Technology of Japan to K. Inai [Grant Numbers 20H03908 and 16K09930]. This work was supported in part by a Grant-in-aid for Scientific Research [18K07670] from the Japan Society for the Promotion of Science to H. Kimura. The funding sources had no role in the study design; in the collection, analysis and interpretation of data; in the writing of the report; and in the decision to submit the article for publication.

\section{Availability of data and materials}

These data will not be shared due to data protection requirements. The full datasets are not openly available. Data can be obtained on reasonable request from the corresponding author. Information about the data and conditions for access are available from the corresponding author (Kiyokadzu Ebata, ebatakiyokadzu@gmail.com).

\section{Declarations}

\section{Ethics approval and consent to participate}

This study was approved by The Research Ethics Committee of University of Fukui (No. 20100064), and written, informed consent was obtained from the family of each deceased patient prior to autopsy for publication of the research and any accompanying images. A copy of the written consent is available for review by the Editor of this journal. This research conformed to the provisions of the Declaration of Helsinki. The datasets generated and/or analyzed during the current study are not publicly available.

\section{Consent for publication}

Consent for publications was obtained from the family of each deceased patient prior to autopsy for publication of the research and any accompanying images.

\section{Competing interests}

The authors declare that they have no conflict of interest.

\section{Author details}

${ }^{1}$ Integrated and Advanced Medical Course, Graduate School of Medical Sciences, University of Fukui, 23-3 Matsuoka Shimoaizuki, Eiheiji-cho, Yoshida-gun, Fukui 910-1193, Japan. ${ }^{2}$ Department of Radiology, University of Fukui Hospital, 23-3 Matsuoka Shimoaizuki, Eiheiji-cho, Yoshida-gun, Fukui 910-1193, Japan. ${ }^{3}$ Faculty of Nursing and Social Welfare Sciences, Fukui Prefectural University, 4-1-1 Kenjojima, Matsuoka, Eiheiji-cho, Yoshida-gun, Fukui 910-1195, Japan. ${ }^{4}$ Division of Molecular Pathology, Department of Pathological Sciences, School of Medical Sciences, University of Fukui, 23-3 Matsuoka Shimoaizuki, Eiheiji-cho, Yoshida-gun, Fukui 910-1193, Japan. ${ }^{5}$ Department of Radiology, Faculty of Medical Science, University of Fukui, 23-3 Matsuoka Shimoaizuki, Eiheiji-cho, Yoshida-gun, Fukui 910-1193, Japan. ${ }^{6}$ Autopsy Imaging Division, Education and Research Center for Medical Imaging, School of Medical Sciences, University of Fukui, 23-3 Matsuoka Shimoaizuki, Eiheiji-cho, Yoshida-gun, Fukui 910-1193, Japan.

Received: 28 April 2021 Accepted: 6 September 2021 Published online: 23 September 2021

\section{References}

1. Wiseman J, Rouleau J, Rigo P, Strauss HW, Pitt B. Gallium-67 myocardial imaging for the detection of bacterial endocarditis. Radiology. 1976;120(1):135-8. https://doi.org/10.1148/120.1.135

2. Thali MJ, Yen K, Plattner T, Schweitzer W, Vock P, Ozdoba C, Dirnhofer RJ. Charred body: virtual autopsy with multi-slice computed tomography and magnetic resonance imaging. J Forensic Sci. 2002;47(6):1326-31. https://doi.org/10.1520/JFS15569J.

3. Sanders I, Woesner ME, Ferguson RA, Noguchi TT. A new application of forensic radiology: identification of deceased from a single clavicle. Am J Roentgenol Radium Ther Nucl Med. 1972;115(3):619-22. https://doi.org/ 10.2214/ajr.115.3.619.

4. Takatsu A, Suzuki N, Hattori A, Shigeta A. The concept of the digital morgue as a 3D database. Leg Med (Tokyo). 1999; (1):29-33. https://doi. org/10.1016/S1344-6223(99)80007-8.
5. MJ Thali, BP Kneubuehl, P Vock, Gv Allmen, R Dirnhofer. High-speed documented experimental gunshot to a skull-brain model and radiologic of virtual autopsy. Am J Forensic Med Pathol. 3(3) (2002) 223-8. doi:https:// doi.org/10.1097/00000433-200209000-00003

6. Ezawa H, Yoneyama R, Kandatsu S, Yoshikawa K, Tsujii H, Harigaya K. Introduction of autopsy imaging redefines the concept of autopsy: 37 cases clinical experience. Pathol Int. 2003;53(12):865-73. https://doi.org/ 10.1046/j.1440-1827.2003.01573.X.

7. Noriki S, lino S, Kinoshita K, Fukazawa Y, Inai K, Sakai T, Kimura H. Pathological analysis of cadavers for educational dissection by using postmortem imaging. Pathol Int. 2019;69(10):580-600. https://doi.org/10.1111/pin. 12857.

8. Noriki S, Kinoshita K, Inai K, Sakai T, Kimura H, Yamauchi T, Iwano M, Naiki $\mathrm{H}$. Newly recognized cerebral infarctions on postmortem imaging: a report of three cases with systemic infectious disease. BMC Med Imaging. 2017;17(1):4. https://doi.org/10.1186/s12880-016-0174-4.

9. Inai K, Noriki S, Kinoshita K, Sakai T, Kimura H, Nishijima A, Iwasaki H, Naiki $\mathrm{H}$. Postmortem CT is more accurate than clinical diagnosis for identifying the immediate cause of death in hospitalized patients: a prospective autopsy-based study. Virchows Arch. 2016;469(1):101-9. https://doi.org/ 10.1007/s00428-016-1937-6.

10. Inai K, Noriki S, Kinoshita K, Nishijima A, Sakai T, Kimura H, Naiki H. Feasibility of liver weight estimation by postmortem computed tomography images: an autopsy study. Pathol Int. 2014;64(7):315-24. https://doi.org/ 10.1111/pin.12174.

11. T. Kodera, H. Arishima, R. Kitai, K. Kikuta, S. lino, S. Noriki, H. Naiki. Utility of postmortem imaging system for anatomical education in skull base surgery. Neurosurg Rev. 38(1) (2015) 165-70 discussion 170. https://doi. org/10.1007/s10143-014-0574-2

12. Shiotani S, Yamazaki K, Kikuchi K, Nagata C, Morimoto T, Noguchi Y, Suzuki M, Atake S, Kohno M, Ohashi N. Postmortem magnetic resonance imaging (PMMRI) demonstration of reversible injury phase myocardium in a case of sudden death from acute coronary plaque change. Radiat Med. 2005;23(8):563-5.

13. Okuda T, Shiotani S, Hayakawa H, Kikuchi K, Kobayashi T, Ohno Y. A case of fatal cervical discoligamentous hyperextension injury without fracture: correlation of postmortem imaging and autopsy findings. Forensic Sci Int. 2013;225(1-3):71-4. https://doi.org/10.1016/j.forsciint.2012.04.035.

14. Jackowski C, Christe A, Sonnenschein M, Aghayev E, Thali MJ. Postmortem unenhanced magnetic resonance imaging of myocardial infarction in correlation to histological infarction age characterization. Eur Heart J. 2006;27(20):2459-67. https://doi.org/10.1093/eurheartj/ehl255.

15. Jackowski C, Warntjes MJB, Berge J, Bär W, Persson A. Magnetic resonance imaging goes postmortem: noninvasive detection and assessment of myocardial infarction by postmortem MRI. Eur Radiol. 2011;21(1):70-8. https://doi.org/10.1007/s00330-010-1884-6.

16. Jackowski C, Schwendener N, Grabherr S, Persson A. Post-mortem cardiac 3-T magnetic resonance imaging: visualization of sudden cardiac death? J Am Coll Cardiol. 2013;62(7):617-29. https://doi.org/10.1016/j.jacc.2013.01. 089.

17. JG Cha, DH Kim, DH Kim, SH Paik, JS Park, SJ Park, HK Lee, HS Hong, DL Choi, KM Yang, NE Chung, BW Lee, JS Seo. Utility of postmortem autopsy via whole-body imaging: initial observations comparing MDCT and 3.0T MRI findings with autopsy findings. Korean J Radiol. 11(4):395-406 (2010). doi:https://doi.org/10.3348/kjr.2010.11.4.395

18. Ross S, Ebner L, Flach P, Brodhage R, Bolliger SA, Christe A, Thali MJ. Postmortem whole-body MRI in traumatic causes of death. AJR Am J Roentgenol. 2012;199(6):1186-92. https://doi.org/10.2214/AJR.12.8767.

19. Dirnhofer R, Jackowski C, Vock P, Potter K, Thali MJ. VIRTOPSY: Minimally invasive, imaging-guided virtual autopsy. Radiographics. 2006;26(5):1305-33. https://doi.org/10.1148/rg.265065001.

20. Cohen MC, Whitby E, Fink MA, Collett JM, Offiah AC. Running a postmortem service: a business case and clinical experience. Pediatr Radiol. 2015;45(4):501-8. https://doi.org/10.1007/s00247-014-3156-0.

21. Ruder TD, Ebert LC, Khattab AA, Rieben R, Thali MJ, Kamat P. Edema is a sign of early acute myocardial infarction of post-mortem magnetic resonance imaging. Forensic Sci Med Pathol. 2013;9(4):501-5. https://doi. org/10.1007/s12024-013-9459-x.

22. Birkl C, Soellradl M, Toeglhofer AM, Krassnig S, Leoni M, Pirpamer L, Vorauer T, Krenn H, Haybaeck J, Fazekas F, Ropele S, Langkammer C. Effects of concentration and vendor specific composition of formalin on 
postmortem MRI of human brain. Magn Reson Med. 2018;79(2):1111-5. https://doi.org/10.1002/mrm.26699.

23. Baba Y, Lerch MM, Stark DD, Tanimoto A, Kreft BP, Zhao L, Saluja AK, Takahashi M. Time after excision and temperature alter ex vivo tissue relaxation time measurements. J Magn Reson Imaging. 1994;4(5):647-51. https://doi.org/10.1002/jmri.1880040504.

24. Nagara H, Inoue T, Koga T, Kitaguchi T, Tateishi J, Goto I. Formalin fixed brains are useful for magnetic resonance imaging (MRI) study. J Neurol Sci. 1987:81(1):67-77. https://doi.org/10.1016/0022-510X(87)90184-5.

25. Tovi M, Ericsson A. Measurements of $\mathrm{T} 1$ and $\mathrm{T} 2$ over time in formalin-fixed human whole-brain specimens. Acta Radiol. 1992;33(5):400-4. https:// doi.org/10.1177/028418519203300503.

26. Pfefferbaum A, Sullivan EV, Adalsteinsson E, Garrick T, Harper C. Postmortem MR imaging of formalin-fixed human brain. Neuroimage. 2004;21 (4):1585-95. https://doi.org/10.1016/j.neuroimage.2003.11.024.

27. Yong-Hing CJ, Obenaus A, Stryker R, Tong K, Sarty GE. Magnetic resonance imaging and mathematical modeling of progressive formalin fixation of the human brain. Magn Reson Med. 2005;54(2):324-32. https:// doi.org/10.1002/mrm.20578.

28. Birkl C, Langkammer C, Golob-Schwarzl N, Leoni M, Haybaeck J, Goessler W, Fazekas F, Ropele S. Effects of formalin fixation and temperature on MR relaxation times in the human brain. NMR Biomed. 2016;29(4):458-65. https://doi.org/10.1002/nbm.3477.

29. AS Shatil, MN Uddin, KM Matsuda1, CR Figley. Quantitative ex vivo MRI changes due to progressive formalin fixation in whole human brain specimens: longitudinal characterization of diffusion, relaxometry, and myelin water fraction measurements at 3T. Front Med 5 (2018) 31. https:// doi.org/10.3389/fmed.2018.00031

30. C J Y-Hing, A Obenaus, R Stryker, K Tong, G E Sarty. Magnetic resonance imaging and mathematical modeling of progressive formalin fixation of the human brain. Magn Reson Med 54(2) (2005) 324-32. doi: https://doi. org/10.1002/mrm.20578.

31. Kanawaku Y, Someya S, Kobayashi T, Hirakawa K, Shiotani S, Fukunaga T, Ohno Y, Kawakami S, Kanetake J. High-resolution 3D-MRI of postmortem brain specimens fixed by formalin and gadoteridol. Leg Med (Tokyo). 2014;16(4):218-21. https://doi.org/10.1016/j.legalmed.2014.03.003.

32. Seifert AC, Umphlett $M$, Hefti M, Fowkes $M$, Xu J. Formalin tissue fixation biases myelin-sensitive MRI. Magn Reson Med. 2019;82(4):1504-17. https://doi.org/10.1002/mrm.27821.

33. Zhou Z, Bai R, Wang Z, Bryant H, Lang L, Merkle H, Munasinghe J, Tang L, Tang W, Tian R, Yu G, Ma Y, Niu G, Gao J, Chen X. An albumin-binding T1T2 dual-modal MRI contrast agents for improved sensitivity and accuracy in tumor imaging. Bioconjug Chem. 2019;30(6):1821-9. https://doi.org/ $10.1021 /$ acs.

34. K. Uchida, H. Nakajima, N. Takeura, T. Yayama, A.R. Guerrero, A. Yoshida, T. Sakamoto, K. Honjoh, H. Baba. Prognostic value of changes in spinal cord signal intensity on magnetic resonance imaging in patients with cervical compressive myelopathy. Spine J;14(8) (2014) 1601-10. doi: https://doi. org/10.1016/j.spinee.2013.09.038.

35. G.R. Moore, E. Leung, A.L. MacKay, I.M. Vavasour, K.P. Whittall, K.S. Cover, D.K. Li, S.A. Hashimoto, J. Oger, T.J. Sprinkle, D.W. Paty. A pathology-MRI study of the short-T2 component in formalin-fixed multiple sclerosis brain. Neurology;55(10) (2000)1506-10. doi: https://doi.org/10.1212/wnl. 55.10 .1506 .

36. Nixon JR, Miller GM, Okazaki H, Gomez MR. Cerebral tuberous sclerosis: postmortem magnetic resonance imaging and pathologic anatomy.
Mayo Clin Proc. 1989;64(3):305-11. https://doi.org/10.1016/s00256196(12)65250-1.

37. Filho GH, Du J, Pak BC, Statum S, Znamorowski R, Haghighi P, Bydder G, Chung CB. Quantitative characterization of the Achilles tendon in cadaveric specimens: $\mathrm{T} 1$ and $\mathrm{T} 2^{*}$ measurements using ultrashort-TE MRI at $3 \mathrm{~T}$. AJR Am J Roentgenol. 2009;192(3):W117-24. https://doi.org/10.2214/AJR. 07.3990.

38. J.-P. Carpenter, T. He, P. Kirk, M. Roughton, L.J. Anderson, S.V. de Noronha, A.J. Baksi, M.N. Sheppard, J.B. Porter, J.M. Walker, J.C. Wood, G. Forni, G. Catani, G. Matta, S. Fucharoen, A. Fleming, M. House, G. Black, D.N. Firmin, T.G. St Pierre, D.J. Pennell. Calibration of myocardial T2 and T1 against iron concentration. J Cardiovasc Magn Reson.; 16(1) (2014) 62. doi: https://doi. org/10.1186/s12968-014-0062-4.

39. Hsu JC, Johnson GA, Smith WM, Reimer KA, Ideker RE. Magnetic resonance imaging of chronic myocardial infarcts in formalin-fixed human au-topsy hearts. Circulation. 1994;89(5):2133-40. https://doi.org/10.1161/ 01.cir.89.5.2133.

40. Scheffler $\mathrm{K}$, Hennig J.T(1) quantification with inversion recovery TrueFISP. Magn Reson Med. 2001;45(4):720-3. https://doi.org/10.1002/mrm.1097.

41. Kanda Y. Investigation of the freely available easy-to-use software "EZR" for medical statistics. Bone Marrow Transplant. 2013;48(3):452-8.

42. Thavarajah R, Mudimbaimannar VK, Elizabeth J, Rao UK, Ranganathan K. Chemical and physical basics of routine formaldehyde fixation. J Oral Maxillofac Pathol. 2012;16(3):400-5. https://doi.org/10.4103/0973-029X. 102496.

43. R D Start,C M Layton,S S Cross, J H Smith. Reassessment of the rate of fixative diffusion. Journal of Clin Pathol. 1992;45(12):1120-1. doi:https://doi. org/10.1136/jcp.45.12.1120

44. Rooney WD, Johnson G, Li X, Cohen ER, Kim S-G, Ugurbil K, Springer CS $\mathrm{Jr}$. Magnetic field and tissue dependencies of human brain longitudinal ${ }^{1} \mathrm{H}_{2} \mathrm{O}$ relaxation in vivo. Magn Reson Med. 2007;57(2):308-18. https://doi. org/10.1002/mrm.21122.

45. J.H. Chen, H.E. Avram, L.E. Crooks, M. Arakawa, L. Kaufman, A.C. Brito. In vivo relaxation times and hydrogen density at $0.003-4.85 \mathrm{~T}$ in rats with implanted mammary adenocarcinomas. Radiology 184(2): 427-34; (1992). doi:https://doi.org/10.1148/radiology.184.2.1620841.

46. Crooks LE, Arakawa M, Hoenninger J, McCarten B, Watts J, Kaufman L. Magnetic resonance imaging : effects of magnetic field strength. Radiology. 1984;151(1):127-33. https://doi.org/10.1148/radiology.151.1.67013 02.

47. C M J de Bazelaire, G D Duhamel, N M Rofsky, D C Alsop. MR Imaging relaxation times of abdominal and pelvic tissues measured in vivo at 3.0 T: preliminary results. Rabdology 230(3):652-9; (2004). doi: https://doi. org/10.1148/radiol.2303021331.

48. Kobayashi T, Isobe T, Shiotani S, Saito H, Saotome K, Kaga K, Miyamoto K, Kikuchi K, Hayakawa H, Akutsu H, Homma K. Postmortem magnetic resonance imaging dealing with low temperature objects. Magn Reson Med Sci. 2010;9(3):101-8. https://doi.org/10.2463/mrms.9.101.

\section{Publisher's Note}

Springer Nature remains neutral with regard to jurisdictional claims in published maps and institutional affiliations.

Ready to submit your research? Choose BMC and benefit from:

- fast, convenient online submission

- thorough peer review by experienced researchers in your field

- rapid publication on acceptance

- support for research data, including large and complex data types

- gold Open Access which fosters wider collaboration and increased citations

- maximum visibility for your research: over $100 \mathrm{M}$ website views per year

At BMC, research is always in progress.

Learn more biomedcentral.com/submissions 